\title{
Die Auffindung und Bestimmung sehr geringer Mengen von Silber.
}

\author{
Von \\ G. Staftord Whitby. ${ }^{1}$
}

Die Bestimmung sehr kleiner Mengen von Silber bietet nach verschiedenen Richtungen Interesse, besonders aber augenblicklich, wo sehr wichtige Atomgewichtsbestimmungen im Gange sind, deren Genauigkeit so grol's ist, dals die Menge des von kaltem Wasser gelösten silberchlorids zu einer Korrektur nötigt, deren Betrag verhältnismälsig grols ist.

Ls wurde gefunden, dafs alle Lösungen von Silbersalzen beim Erhitzen mit etwas Natriumbydroxyd und einer bestimmten Art von organischen Verbindungen eine braune oder gelbe Färbung liefern. selbst wenn die vorhandene Silbermenge sehr gering ist. $50 \mathrm{ccm}$ einer Lösung von einem Teil Silber in 25000000 Teilen gibt eine dentliche Färbung bei Anwendung des unten beschriebenen Verfahrens. Wenn die $50 \mathrm{ccm}$ der für diese Probe verwendeten Lösung mehr als $0.000025 \mathrm{~g}$ Silber enthalten, ist die auftretende Färbung so tief, dal's sie erkannt werden kann, ohne dafs es nötig wäre, die Flüssigkeit in ein Nesstersches Glas überzuführen.

Die organischen Substanzen, die diese Färbung beim Erhitzen mit natriumbydroxydhaltigen Silberlösungen geben können, sind nach den bisherigen Beobachtungen die folgenden: Dextrin, Gummi arabicum, Glycerin, Cellulose (in Form von Filterpapier), Stärke und Rohrzucker. Die Methode kanm ausgedehnt werden auf die quantitative Bestimmung sehr kleiner Silbermengen, da die in der Lösung hervorgerufene Färbung genau dem vorhandenen Silber proportional ist. Am geeignetsten von den erwähnten Substanzen ist Rohrzucker; die Arbeitsweise ist folgende: Die Silberlösung wird in geeigneter Weise verdünnt, und $50 \mathrm{ccm}$ davon werden mit einigen Tropfen einer ziemlich konzentrierten Zuckerlösung versetzt. Der Becher von $150 \mathrm{ccm}$ mit der Flüssigkeit wird 2 Minuten in ein siedendes

\footnotetext{
1 Aus dem Manuskript ins Deutselse übertragen von I. Kopfec-Berlin.
} 
Wasserbad eingetaucht, worauf man ungefähr 6 Tropfen einer Normallösung von Natriumhydroxyd hinzufügt und weitere 20-30 Sekunden, nachdem die Farbe sich entwickelt hat, erhitzt, aber insgesamt nicht länger als 2 Minuten, da Silber nicht vorhanden ist, wenn sich nach dieser Zeit keine Farbe zeigt. Die Lösung wird abgekühlt, in ein NessLersches Glas gebracht und die Intensität der gelben Farbe gegen eine Normalfärbung von ungeführ derselben Intensität bestimmt. Die Vergleichslösung, die an demselben Tage benutzt werden sollte, an dem sie hergestellt ist, bereitet man zweckmälsig aus $50 \mathrm{ccm}$ einer Silbernitratlösung mit $0.000001 \mathrm{~g}$ Silber im Kubikzentimeter. Hierdurch ist es möglich $0.000002 \mathrm{~g}$ Silber in $50 \mathrm{ccm}$ Lösung oder $0.00004 \mathrm{~g}$ Silber im Liter $\mathrm{zu}$ bestimmen.

Die Methode besitzt Wert zur Messung der Korrektion für die Löslichkeit von Silberhalogeniden in Wasser bei genauen gravimetrischen Untersuchungen, z. B. bei Atomgewichtsbestimmungen. Sie ist ungefähr von derselben Empfindlichkeit wie die Nephelometermethode von RICHARDS und WnLLs, ${ }^{1}$ aber sie lälst sich leichter und schneller ausführen und bedingt keine Komplikationen.

Bei der Ausführung des soeben beschriebenen Verfahrens zur Silberbestimmung darf Ammoniak nicht vorhanden sein, dagegen stören andere Metalle, wie Kupfer, Zink, ein- oder zweiwertiges Quecksilber, Wismut, Cadmium und Blei, wenn ihre Mengen etwa ebensoviel betragen, wie die des Silbers, d. h. wenn sie mit Natriumhydroxyd keinen merklichen Niederschlag geben, nicht die Entwickelung der Farbe. Das Verhalten des Bleis wird noch weiter untersucht.

Eine Erklärung des Mechanismus der Reaktion, durch die die Farbe entsteht, kann gegeben werden. Die Färbung, die durch Einwirkung einer der verschiedenen organischen Stoffe und Natriumhydroxyd auf Silberlösungen eintritt, ist auf die Gegenwart von kolloidalem Silber zurückzuführen. Die Lösungen geben den Tyndalleffekt, werden durch geringe Mengen Salzsäure gefälit und besitzen auch die übrigen Eigenschaften kolloidaler Silberlösungen. Weiterhin gibt auch eine Lösung von Silberoxyd beim Kochen mit Rohrzucker ohne Zusatz von Natriumhydroxyd die Gelbfärbung. Aber keine andere Silberverbindung verhält sich ebenso; die andern erfordern alle die Gegenwart von Natriumhydroxyd, um die Färbung

1 Amer. Chem. Journ. 31 (1904), 235. 
zu liefern. Es scheint demnach, dafs das Natriumbydroxyd die Silbersalze in Silberhydroxyd überführt, das dann direkt mit den organischen Substanzen reagiert. Alle verwendeten organischen Stoffe sind Kohlehydrate und Hydroxylverbindungen, und es ist wahrscheinlich, dafs ein Wasserstoffion vom organischen Molekül abgespalten wird, die Ladung des Silberions aufnimmt und sich mit dem Hydroxylion des Silberhydroxyds zu nicht dissoziiertem Wasser vereinigt. Das seiner Ionenladung beraubte Silber geht in kolloidale Lösung über.

Hiermit stimmt überein, dals andere Alkalien, wie Barytwasser, das Natriumhydroxyd ersetzen können und dafs Natriumbydroxyd kein Katalysator der Reaktion ist, da eine gewisse minimale Menge nutwendig ist, um die vollständige Färbung zu entwickeh, nämlich so viel wie dem Silber in der Lösung entspricht.

London, Royal College of Science, Analytical Laboratories.

Bei der Redaktion eingegangen am 26. Februar 1910. 